\title{
Willingness to use pre-exposure prophylaxis for HIV prevention among female sex workers: a cross-sectional study in China
}

This article was published in the following Dove Press journal:

HIVIAIDS - Research and Palliative Care

2I September 2012

Number of times this article has been viewed

\section{Bin Peng ${ }^{1,2}$ \\ Xiaowei Yang ${ }^{2}$ \\ Yan Zhang' \\ Jianghong $\mathrm{Dai}^{3}$ \\ Hao Liang ${ }^{4}$ \\ Yunfeng Zou ${ }^{4}$ \\ Jinkun Luo ${ }^{5}$ \\ Hongbin Peng ${ }^{5}$ \\ Xiaoni Zhong' \\ Ailong Huang 6}

'School of Public Health, Chongqing Medical University, Chongqing, China; ${ }^{2}$ Division of Biostatistics, School of Medicine, University of California, Davis, CA, USA; ${ }^{3}$ School of Public Health, Xinjiang Medical University, Xinjiang, China; ${ }^{4}$ School of Public Health, Guangxi Medical University, Nanning, China; ${ }^{5}$ Shunqing Center for Disease Control and Prevention, Nanchong, Sichuan, China; ${ }^{6}$ Virus Hepatitis Research Institute of Chongqing Medical University, Chongqing, China
Correspondence: Xiaoni Zhong I Yixueyuan Road, Yuzhong District, Chongqing, 400016, China

Tel +862368485259

Fax +862368485008

Email zxn66@vip.sina.com
Background: Pre-exposure prophylaxis (PrEP) is a strategy developed to prevent individuals who are human immunodeficiency virus (HIV)-negative from developing HIV infection. In China, while conducting a clinical trial to investigate the effectiveness and safety of PrEP, we performed this survey to assess the willingness of female sex workers to use PrEP, and identify predictors of this willingness.

Methods: From July 2009 to April 2010, a cross-sectional study was carried out in four provinces of China. We recruited 1611 female sex workers who completed a self-administered survey to assess their awareness of and intention to use PrEP. The survey also canvassed demographic, behavioral, and psychosocial variables. Bivariate and multivariable logistic regression models were fitted to identify predictors of intent to use PrEP.

Results: In total, $69 \%$ of the women (95\% confidence interval [CI] 66.7-71.3) reported intent to use PrEP, and $12 \%$ (95\% CI 10.5-13.7) had used drugs in the past to prevent a sexually transmitted infection. Further, 16.5\% (95\% CI 14.7-18.4) had previously heard of PrEP, and $1.4 \%$ (95\% CI 0.9-2.1) had used PrEP previously to prevent HIV infection. Multivariate analysis indicated the following significant predictors of intent to use PrEP: Han ethnicity (adjusted odds ratio $[\mathrm{AOR}] 1.446 ; P=0.011$ ), urban residence (AOR 1.302; $P=0.027$ ), knowledge about transmission of HIV/acquired immune deficiency virus syndrome (AIDS, AOR 1.817; $P=0.0007$ ), a history of sexually transmitted infection (AOR 1.830; $P<0.0001$ ), a history of using medication to prevent a sexually transmitted disease (AOR 2.547; $P<0.0001$ ), and willingness to access knowledge about HIV/AIDS (AOR 2.153; $P<0.0001$ ).

Conclusion: The majority of female sex workers reported intent to use PrEP if it is safe and effective. Given that most of the participants had never heard of PrEP before, we strongly recommend that educational materials be developed with detailed introduction of PrEP. The risks and benefits of PrEP use should be fully explained to potential users when promoting PrEP in the future.

Keywords: human immunodeficiency virus, infection, pre-exposure prophylaxis, PrEP, willingness, female sex workers

\section{Introduction}

In the past 30 years, acquired immune deficiency syndrome (AIDS) has been quickly spreading to almost every corner of the world. A well known threat to humans, AIDS has created many challenges and placed a heavy burden on our global public health system. At the end of 2010, about 34 million people were living with human immunodeficiency virus (HIV) worldwide. This number is 17\% higher than that in 2001 and includes 2.7 million new HIV infections in 2010. ${ }^{1}$ Although the HIV prevalence rate is low in Asia, the continent still has the second largest HIV population. 
By the end of 2011, it was reported that 0.78 million people were living with HIV/AIDS in China, ${ }^{2}$ with $46.5 \%$ infected by heterosexual transmission and $17.4 \%$ by homosexual contact. In 2011, the national prevalence of HIV was $0.058 \%$, with 48,000 new infections. Even though the prevalence remains low in China nationwide, challenges in HIV/AIDS prevention and control remain critical in certain regions and populations. For example, five provinces account for $60 \%$ of the total population with HIV/ AIDS in China. ${ }^{2}$

Although the prevalence of HIV among female sex workers is relatively low nationwide, and was only $0.3 \%$ in 2011 , it exceeded $1 \%$ in the same year at sentinel surveillance sites for female sex workers located in five provinces of China. ${ }^{3}$ In 2009, it was estimated that there were 2.68 million female sex workers and 26.5 million clients of female sex workers in China. ${ }^{4}$ In the urban areas of Guiyang and Xingyi, the estimated number of female sex workers accounted for $3.4 \%$ and $3.6 \%$ of the local urban female population, respectively. ${ }^{5}$ There is a significant risk of sexually transmitted diseases spreading from female sex workers to their long-term partners or even spreading to the general population through their clients. ${ }^{6,7}$

HIV control still looks grim in China. In order to prevent transmission and spread of HIV, various strategies and methods have been considered. It was expected that a safe and effective HIV vaccine would be developed, but this has proved to be extremely challenging due to technical and implemental difficulties. Although there do exist some solutions for HIV infection prevention and control (eg, sexual health education, proper condom use, disposable needles, treatment of infection, and circumcision), their effectiveness has been limited. Therefore, it is important and urgent that we develop more effective and affordable prevention strategies in China to contain the spread of HIV/AIDS from female sex workers and their sexual clients.

Pre-exposure prophylaxis (PrEP), which is a potentially effective strategy for biomedical prevention, has been the focus of recent studies. ${ }^{8-13}$ Through oral administration of antiretroviral drugs or use of microbicides with antiretroviral activity, PrEP is a strategy to prevent HIV-negative individuals from becoming infected with HIV. Until February 2011, there were more than ten clinical studies of PrEP ongoing throughout the world, and distributed across 12 countries including Africa, Asia, Latin America, and the US. ${ }^{14}$ A study in nearly 900 African women showed for the first time that the tested anti-HIV vaginal gel was associated with a 39\% lower risk of HIV infection than placebo. ${ }^{15}$ More promising, the recent
iPrEx trial results suggested that in gay men, transgender women, and other men who have sex with men (MSM), daily TDF-FTC (tenofovir disoproxyl fumarate plus emtricitabine, also known as Truvada ${ }^{\circledR}$ ) reduces the risk of HIV by $44 \% .^{14,16}$ The Partners PrEP study showed that TDF and TDF-FTC taken daily both reduce the risk of HIV transmission among both men and women by $62 \%$ and $73 \%$, respectively. ${ }^{14}$ The TDF2 study also indicated that daily oral TDF-FTC was associated with a $62.6 \%$ lower risk of HIV infection in both male and female participants. ${ }^{14}$ On the other hand, two trials, ie, FEM-PrEP (use of PrEP for HIV prevention among heterosexual women) and VOICE (Vaginal and Oral Interventions to Control the Epidemic), were terminated due to lack of effectiveness. ${ }^{14}$ Nonetheless, once the efficacy of PrEP is proven to be without safety issues by further studies, it would have a high impact on HIV prevention. The PrEP strategy not only complements other existing prevention methods, but also has some unique advantages. For example, it does not require compliance from sexual partners.

The success of the PrEP strategy depends heavily on the user's willingness to use it, and also involves a level of user awareness, acceptance, and compliance. Under the premise that PrEP has not yet been proven to be safe and effective, little research on the willingness to use it has been conducted. A study of 42 subjects indicated that, among the various features of PrEP (including price, efficiency, side effects, and duration of treatment), the most important ones included price, efficacy, and safety, but did not include duration of treatment. Note that PrEP would require routine treatment for at least 10 years. ${ }^{17} \mathrm{~A}$ survey of $227 \mathrm{MSM}$ in Boston, MA, suggested that about $74.4 \%$ participants expressed willingness to use PrEP, but the willingness level varied greatly between demographic groups. For instance, $48.6 \%$ of those with a college degree were willing to use PrEP, compared with $90.9 \%$ of those with high school or lower education. ${ }^{8}$ Currently, we are planning to conduct a large-scale clinical trial of PrEP in China, mainly targeting high-risk populations, such as female sex workers and MSM. This survey was conducted mainly to assess the willingness of female sex workers in western China to use PrEP and to identify significant predictors of willingness. As a feasibility study for the clinical trial, the survey will also provide evidence and information for future promotion of PrEP among female sex workers in China.

\section{Materials and methods Design and participant recruitment}

Our research team conducted a cross-sectional study between July 2009 and April 2010 in four provinces of China, 
ie, Chongqing, Guangxi, Xinjiang, and Sichuan. The four sites in this study were specifically chosen because of their markedly higher incidences of HIV infection, wide diversity of infected groups, and the higher prevalence of drug abuse and the sex trade in western regions of China. ${ }^{2,3}$ The target population for this study was female sex workers, who have a high risk of contracting HIV/AIDS. Considering that female sex workers frequently change business locations and sexual services are illegal in China, it is very difficult to estimate the number of female sex workers and their geographic distribution. This study adopted a nonprobability sampling method when recruiting participants, especially for "seed" subjects, ie, those who were recruited earlier and were willing to provide references. We advertised through local media (eg, newspapers and leaflets) and the local branches of the Centers for Disease Control and Prevention. At the same time, the seed participants helped to recruit other female sex workers by peer referral, enabling more participants to be added to the study in the form of a "rolling snowball".

During the study, all participants were asked to complete a self-administered quantitative questionnaire under the guidance of interviewers. Most participants completed the questionnaire in 30-40 minutes and each received $50 \mathrm{RMB}$ (Chinese dollars) as an incentive. Before conducting the survey, the study protocol and institutional review board application were reviewed and approved by the local ethics review committee of Chongqing Medical University. All participants signed an "informed consent" form describing how privacy was ensured before they contributed any data to the study.

\section{Measures}

\section{Demographic information}

Socioeconomic characteristics of participants including age, marital status, race, residence, education, and income were collected.

\section{Knowledge, behavior, and awareness of HIV/AIDS}

Thirteen questions concerning knowledge about infection and prevention of HIV/AIDS were used to assess the level of awareness about HIV/AIDS, eg, "Does AIDS spread through mosquito bites?", "Does AIDS spread through coughing, sneezing?", and "Would anyone who dines with HIV carriers or patients get HIV infected?" HIV/AIDS-related risk behaviors were enquired about, eg, any history or previous diagnosis of a sexually transmitted infection, whether an HIV consultation had ever been sought, previous testing for HIV, medication to prevent sexually transmitted infection, awareness of post-exposure prophylaxis, awareness of vaginal microbicides, condom use, and history of substance and/or alcohol abuse. The questionnaire also included a question on the willingness of participants to access knowledge about HIV/AIDS.

\section{PrEP use and intention}

At the beginning of the survey, each participant was given a brief introduction to PrEP as a form of preventive medication taken before having sex to prevent HIV infection. The participants were then asked about their history of PrEP use and their willingness to use PrEP in the future, "Assuming that PrEP is safe and effective in preventing HIV, how likely would you use it?". The level of willingness of PrEP use was recorded on a five-point scale of: 1 , definitely; 2 , probably; 3 , not sure; 4, probably not; and 5, definitely not. For data analysis, the willingness scale was further dichotomized into "willing" (definitely or probably) and "unwilling" (probably not, definitely not, or not sure). Some further hypothetical questions were asked to assess the participants' intentions to use PrEP: "Suppose that PrEP is safe and effective in preventing HIV, how likely would you use it if it were available for free?", "How likely would you use it if it were available for free and used by very few people?", and "How likely would you use it if it were available for free and used by a fair large number of people?"

\section{Data analysis}

We used EpiData 3.0 for Windows (EpiData Association, Odense, Denmark) as the software package for double-entry and management of the survey data. Statistical analyses were done using SAS 9.1 for Windows (SAS Institute Inc, Cary, $\mathrm{NC}$ ), whereby statistical significance was determined at the level of $\alpha=0.05$. Univariate descriptive statistics included mean and variance for quantitative variables and frequency and percentage for qualitative variables. The prevalence of PrEP use and intention to use were calculated with $95 \%$ confidence intervals (CI). Univariate logistic regression was first applied to select variables that were individually significantly associated with the outcome variable (ie, willingness to use PrEP). Multivariate logistic regression was then fitted to determine the joint influence of predictors on the outcome variable. Odds ratios (ORs) and their 95\% CI were reported to evaluate the influence of predictor variables. It was assumed that PrEP use is hypothetically safe and effective throughout the study.

\section{Results Demographics}

The study recruited 1611 female sex workers who completed the self-administered questionnaire. Participant 
demographics stratified by willingness to use PrEP are shown in Table 1 (willing versus unwilling). The average age of the participants was 26.8 (median 25, range 16-53) years. About $60 \%$ of the female sex workers were self-identified as rural residents. Regarding participant education, 52.3\% had completed junior high school education, $32.5 \%$ had completed senior high school education, and only $15.2 \%$ had college or higher level of education experience. The majority of participants were self-reported as unmarried (63.4\%), while $27.3 \%$ reported being married, 9.3\% reported being divorced or widowed, and $32.4 \%$ of participants reported having children. Most of the participants (47.5\%) reported receiving a monthly income of 1000-3000 RMB, 28.6\% had a monthly income of 3000-5000 RMB, $12.7 \%$ had a monthly income of 5000+ RMB, and $11.2 \%$ had a monthly income of $<1000 \mathrm{RMB}$.

\section{Willingness to use PrEP}

Our study showed that, assuming PrEP to be safe and effective, $55 \%$ of the 1161 female sex workers said they would "definitely" use it, and 14\% said they would "probably" use it. In contrast, only $10.1 \%$ and $11 \%$ participants, respectively, indicated that they would "definitely not" or "probably not" use PrEP. According to the earlier definition of "willingness to use PrEP", 69\% of participants expressed positive responses (95\% CI 66.7-71.3, see Table 2).

When it was assumed that "PrEP drugs will be provided for free", willingness to use PrEP increased to $72.6 \%(95 \%$ CI 70.3-74.7). When it was assumed that the PrEP would be freely provided and "a few people" had already been using it, the willingness rose to $77 \%$ (95\% CI 74.9-79.1). When "a few people" was changed to "a lot more people", the willingness was further increased to $80.6 \%(95 \% \mathrm{CI}$ 78.6-82.5).

\section{HIV/AIDS-related knowledge, behavior, and attitudes}

Participants' attitudes toward AIDS and PrEP use are shown in Table 3, ie, $93.8 \%$ of participants considered AIDS to be a serious or very serious disease, $76.7 \%$ worried about the threat of HIV/AIDS to themselves or their families, and only less than $16 \%$ indicated little or no worry about AIDS at all. Almost all (95\%) participants expected to be able to access knowledge on HIV/AIDS prevention.

Table I Demographic characteristics of female sex workers and willingness to use PrEP

\begin{tabular}{|c|c|c|c|c|c|}
\hline Characteristic & $\begin{array}{l}\text { Total } \\
\text { n (\%) }\end{array}$ & $\begin{array}{l}\text { Willingness } \\
\text { to use PrEP }\end{array}$ & $\begin{array}{l}\text { Unwillingness } \\
\text { to use PrEP }\end{array}$ & OR (95\% Cl) & $P$ value \\
\hline \multicolumn{6}{|l|}{ Age (years) } \\
\hline Mean (range) & $26.8(16-53)$ & $27.0(\mid 7-52)$ & $26.5(16-53)$ & & \\
\hline Median (QI-Q3) & $25.0(22-31)$ & $25.0(22-3 I)$ & $25.0(22-30)$ & & \\
\hline Race & & & & & 0.011 \\
\hline Han & I 327 (82.4) & $934(70.4)$ & $393(29.6)$ & $1.415(1.083-1.850)$ & \\
\hline Others & $284(17.6)$ & $178(62.7)$ & $106(37.3)$ & 1.000 & \\
\hline Registered residency & & & & & 0.009 \\
\hline Rural residency & $972(60.6)$ & $649(66.8)$ & $323(33.2)$ & 1.000 & \\
\hline Urban residency & $632(39.4)$ & $46 \mid(72.9)$ & $|7|(27.1)$ & $1.342(1.076-1.673)$ & \\
\hline Education & & & & & 0.649 \\
\hline Elementary school & $244(I 5.2)$ & $164(67.2)$ & $80(32.8)$ & 1.000 & \\
\hline Junior high school & $840(52.3)$ & $588(70.0)$ & $252(30.0)$ & I.I 38 (0.839-I.545) & \\
\hline Senior high school and beyond & $521(32.5)$ & $356(68.3)$ & $165(31.7)$ & $1.052(0.76 \mathrm{I}-1.456)$ & \\
\hline Marital status & & & & & 0.107 \\
\hline Unmarried & $1020(63.4)$ & $696(68.2)$ & $324(31.8)$ & 1.000 & \\
\hline Married & $440(27.3)$ & $300(68.2)$ & $140(31.8)$ & $0.998(0.786-1.268)$ & \\
\hline Others (divorced or widowed) & $150(9.3)$ & 115 (76.7) & $35(23.3)$ & $1.529(1.024-2.283)$ & \\
\hline Have children & & & & & 0.140 \\
\hline Yes & $518(32.4)$ & $370(71.4)$ & $148(28.6)$ & I.189 (0.945-I.495) & \\
\hline No & $1080(67.6)$ & $732(67.8)$ & $348(32.2)$ & 1.000 & \\
\hline Income per month & & & & & 0.006 \\
\hline$\leq 1000 \mathrm{RMB}$ & $181(\mid 1.2)$ & 117 (64.6) & $64(35.4)$ & $0.474(0.300-0.748)$ & 0.001 \\
\hline I00I-3000 RMB & $764(47.5)$ & $520(68.1)$ & $244(31.9)$ & $0.553(0.38 \mathrm{I}-0.80 \mathrm{I})$ & 0.002 \\
\hline $300 \mathrm{I}-5000 \mathrm{RMB}$ & $460(28.6)$ & $311(67.6)$ & $149(32.4)$ & $0.54 I(0.366-0.800)$ & 0.002 \\
\hline$>5000$ RMB & $204(12.7)$ & $162(79.4)$ & $42(20.6)$ & 1.000 & \\
\hline
\end{tabular}

Note: RMB, Chinese dollars.

Abbreviations: $\mathrm{Cl}$, confidence interval; OR, odds ratio; PrEP, pre-exposure prophylaxis. 
Table 2 Willingness to use PrEP in four hypothetical situations

\begin{tabular}{cllll}
\hline $\begin{array}{l}\text { Willingness } \\
\text { to use PrEP }\end{array}$ & $\begin{array}{l}\text { Safe and } \\
\text { effective }\end{array}$ & $\begin{array}{l}\text { Safe, effective, } \\
\text { and free }\end{array}$ & $\begin{array}{l}\text { Safe, effective, free, } \\
\text { and a few are using }\end{array}$ & $\begin{array}{l}\text { Safe, effective, free, } \\
\text { and some are using }\end{array}$ \\
\hline Willing & $1112(69.0)$ & $1169(72.6)$ & $1241(77.0)$ & $1298(80.6)$ \\
$95 \% \mathrm{Cl}$ & $66.7-71.3$ & $70.3-74.7$ & $74.9-79.1$ & $78.6-82.5$ \\
Definitely & $886(55.0)$ & $98 I(60.9)$ & $1068(66.3)$ & $1110(68.9)$ \\
Probably & $226(14.0)$ & $188(11.7)$ & $173(10.7)$ & $188(11.7)$ \\
Unwilling & $499(31.0)$ & $442(27.4)$ & $370(23.0)$ & $313(19.4)$ \\
Not sure & $159(9.9)$ & $119(7.4)$ & $97(6.0)$ & $47(2.9)$ \\
Probably not & $177(11.0)$ & $169(10.5)$ & $144(8.9)$ & $153(9.5)$ \\
Definitely not & $163(10.1)$ & $154(9.6)$ & $129(8.0)$ & $113(7.0)$ \\
\hline
\end{tabular}

Abbreviations: $\mathrm{Cl}$, confidence interval; PrEP, pre-exposure prophylaxis.

The results (Table 4) showed that only 14\% managed to answer all 13 questions on knowledge of HIV/AIDS correctly; $20.1 \%$ incorrectly answered one question, $21.2 \%$ incorrectly answered two questions; and $44.7 \%$ had three or more questions with wrong answers. More than half of the participants $(52.5 \%)$ said that they had recently received a free consultation on AIDS, and $61 \%$ reported having had HIV tests, of which $78 \%$ were offered free of charge.

The survey on AIDS-related behavior (Table 4) showed that $35.1 \%$ of female sex workers had observed symptoms of venereal disease, but less than $10 \%$ of them reported having been diagnosed with a sexually transmitted disease. About half (51.1\%) of participants indicated that they had never consumed alcohol, and only 5.7\% reported use of illicit drugs within the last 6 months. Among drug users, $63 \%$ reported using "K powder" (ketamine); other drugs included ecstasy (30.4\%), methamphetamine hydrochloride (30.4\%), heroin (8.7\%), cannabis (5.4\%), and Magu (4.3\%); and nobody reported use of opium, pethidine, or morphine. About half of the drug users (47\%) reported using drugs before having sex.

\section{Awareness and application of HIVIAIDS prevention strategies}

Our study shows that 194 (12\%) female sex workers reported previous use of medication for a sexually transmitted infection and $22(1.4 \%)$ had previously taken medication preventive against HIV (see Table 4). Meanwhile, 16.5\% of participants reported having heard of PrEP from various sources, ie, doctors $(27 \%)$, researchers $(26 \%)$, online media (16\%), television (15\%), friends (14\%), and newspapers $(9 \%)$. With regard to post-exposure prophylaxis, nearly $20 \%$ participants reported having heard of it from the following sources: doctors $(28 \%)$, researchers $(24 \%)$, friends $(16 \%)$, television $(12 \%)$, online media $(10 \%)$, and newspapers (8\%). Nearly $30 \%$ of the female sex workers interviewed had heard of "vaginal/rectal microbicides" from the following sources: doctors (34\%), television (23\%), friends $(20 \%)$, the survey staff $(17 \%)$, online media $(7 \%)$, and newspapers (7\%). Regarding condom use, more than $80 \%$ of the participants said they "always used" condoms when having sex with clients, while only $2 \%$ said they "never used" condoms.

Table 3 Measures of attitudes toward AIDS and willingness to use PrEP

\begin{tabular}{|c|c|c|c|c|c|}
\hline Characteristic & $\begin{array}{l}\text { Total } \\
\text { n (\%) }\end{array}$ & $\begin{array}{l}\text { Willingness } \\
\text { to use PrEP }\end{array}$ & $\begin{array}{l}\text { Unwillingness } \\
\text { to use PrEP }\end{array}$ & OR $(95 \% \mathrm{CI})$ & $P$ value \\
\hline \multicolumn{5}{|l|}{ Is AIDS serious } & 0.408 \\
\hline Yes & I $492(93.8)$ & $1034(69.3)$ & $458(30.7)$ & I. $199(0.780-1.844)$ & \\
\hline No & $98(6.2)$ & $64(65.3)$ & $34(34.7)$ & 1.000 & \\
\hline \multicolumn{5}{|c|}{ Worried about family members infected with HIV } & 0.091 \\
\hline Yes & $1219(76.7)$ & $855(70.1)$ & $364(29.9)$ & I.237 (0.967-I.583) & \\
\hline No & $371(23.3)$ & $243(65.5)$ & $128(34.5)$ & 1.000 & \\
\hline \multicolumn{5}{|c|}{ Wish to access knowledge of HIVIAIDS } & $<0.0001$ \\
\hline Yes & I53I (95.0) & $1073(70.1)$ & $458(29.9)$ & $2.462(1.567-3.869)$ & \\
\hline No & $80(5.0)$ & $39(48.8)$ & $4 \mid(5 I .3)$ & 1.000 & \\
\hline \multicolumn{5}{|c|}{ Attitude toward HIV/AIDS patients } & 0.009 \\
\hline Discriminatory & $308(19.4)$ & $196(63.6)$ & $112(36.4)$ & 1.000 & \\
\hline Hard to say & $467(29.4)$ & $313(67.0)$ & $154(33.0)$ & I.I6I (0.859-I.57I) & 0.331 \\
\hline Non-discriminatory & $813(51.2)$ & $589(72.4)$ & $224(27.6)$ & 1.503 (I.I37-I.985) & 0.004 \\
\hline
\end{tabular}

Abbreviations: AIDS, acquired immune deficiency syndrome; $\mathrm{Cl}$, confidence interval; $\mathrm{HIV}$, human immunodeficiency virus; OR, odds ratio; PrEP, pre-exposure prophylaxis. 
Table 4 AIDS-related knowledge, behavior, and willingness to use PrEP

\begin{tabular}{|c|c|c|c|c|c|}
\hline Characteristic & $\begin{array}{l}\text { Total } \\
\text { n (\%) }\end{array}$ & $\begin{array}{l}\text { Willingness } \\
\text { to use PrEP }\end{array}$ & $\begin{array}{l}\text { Unwillingness } \\
\text { to use PrEP }\end{array}$ & OR $(95 \% \mathrm{CI})$ & $P$ value \\
\hline \multicolumn{5}{|l|}{ STI history } & $<0.000$ I \\
\hline Yes & $565(35.1)$ & $436(77.2)$ & $129(22.8)$ & $\mathrm{I} .850(\mathrm{I} .464-2.337)$ & \\
\hline No & $1046(64.9)$ & $676(64.6)$ & $370(35.4)$ & 1.000 & \\
\hline \multicolumn{5}{|c|}{ Previous STI diagnosis } & 0.006 \\
\hline Yes & $156(9.7)$ & $123(78.8)$ & $33(2 \mid .2)$ & $1.758(1.179-2.622)$ & \\
\hline No & $1454(90.3)$ & $988(68.0)$ & $466(32.0)$ & 1.000 & \\
\hline \multicolumn{5}{|l|}{ Alcohol } & 0.028 \\
\hline Yes & $786(48.9)$ & $563(71.6)$ & $223(28.4)$ & $1.269(1.027-1.569)$ & \\
\hline No & $822(5 \mathrm{I} . \mathrm{I})$ & $547(66.5)$ & $275(33.5)$ & 1.000 & \\
\hline \multicolumn{5}{|c|}{ Ever used illicit substances } & 0.408 \\
\hline Yes & $92(5.7)$ & $60(65.2)$ & $32(34.8)$ & $0.830(0.533-1.292)$ & \\
\hline No & $1516(94.3)$ & $1051(69.3)$ & $465(30.7)$ & 1.000 & \\
\hline \multicolumn{5}{|c|}{ Has HIVIAIDS transmission knowledge ${ }^{a}$} & 0.002 \\
\hline Yes & $226(14.0)$ & $176(77.9)$ & $50(22.1)$ & $1.689(1.210-2.357)$ & \\
\hline No & $1385(86.0)$ & $936(67.6)$ & $449(32.4)$ & 1.000 & \\
\hline \multicolumn{5}{|c|}{ Ever received free consultation for HIVIAIDS } & 0.003 \\
\hline Yes & $845(52.5)$ & $611(72.3)$ & $234(27.7)$ & $1.379(1.115-1.704)$ & \\
\hline No & $764(47.5)$ & $500(65.4)$ & $264(34.6)$ & 1.000 & \\
\hline \multicolumn{5}{|c|}{ Ever tested for HIV } & 0.084 \\
\hline Yes & $981(6 I .0)$ & $693(70.6)$ & $288(29.4)$ & $1.209(0.975-1.499)$ & \\
\hline No & $628(39.0)$ & $418(66.6)$ & $210(33.4)$ & 1.000 & \\
\hline \multicolumn{5}{|l|}{ Condom use } & 0.110 \\
\hline Every time & $\mathrm{I}, 294(80.5)$ & $905(69.9)$ & $389(30.1)$ & $1.237(0.953-1.606)$ & \\
\hline Other & $314(19.5)$ & $205(65.3)$ & $109(34.7)$ & 1.000 & \\
\hline \multicolumn{5}{|c|}{ Ever used STI preventive medication } & $<0.0001$ \\
\hline Yes & $194(12.0)$ & $160(82.5)$ & $34(17.5)$ & $2.299(1.562-3.383)$ & \\
\hline No & I,417 (88.0) & $952(67.2)$ & $465(32.8)$ & 1.000 & \\
\hline \multicolumn{5}{|c|}{ Ever used HIV preventive medication } & 0.931 \\
\hline Yes & $22(1.4)$ & $15(68.2)$ & $7(31.8)$ & $0.96 I(0.389-2.37 \mathrm{I})$ & \\
\hline No & $1,589(98.6)$ & $1097(69.0)$ & $492(31.0)$ & 1.000 & \\
\hline \multicolumn{5}{|c|}{ Aware of vaginal microbicides } & 0.104 \\
\hline Yes & $475(29.5)$ & $314(66.1)$ & I6I (33.9) & $0.827(0.658-1.040)$ & \\
\hline No & $\mathrm{I}, 135(70.5)$ & $797(70.2)$ & $338(29.8)$ & 1.000 & \\
\hline \multicolumn{5}{|l|}{ Awareness of PEP } & 0.654 \\
\hline Yes & $317(19.7)$ & $222(70.0)$ & $95(30.0)$ & I.063 (0.8|4-I.389) & \\
\hline No & $1292(80.3)$ & $888(68.7)$ & $404(31.0)$ & 1.000 & \\
\hline \multicolumn{5}{|c|}{ Awareness of PrEP } & 0.089 \\
\hline Yes & $265(16.5)$ & $|7|(64.5)$ & $94(35.5)$ & $0.786(0.596-1.038)$ & \\
\hline No & $1342(83.5)$ & $937(69.8)$ & $405(30.2)$ & 1.000 & \\
\hline
\end{tabular}

Notes: ${ }^{\text {a }} 3$ items in total; yes $=$ all of 13 answers were corrected; no $=$ others.

Abbreviations: AIDS, acquired immune deficiency syndrome; Cl, confidence interval; HIV, human immunodeficiency virus; OR, odds ratio; PEP, Post-exposure prophylaxis; PrEP, pre-exposure prophylaxis; STI, sexually transmitted infection.

\section{Participants' concerns about PrEP}

Participants were concerned about the safety (81.6\%), efficacy $(81.0 \%)$, cost (51.2\%), convenience (19.2\%), and accessibility (16.6\%) of PrEP drugs. Regarding costs, $20.6 \%$ of the study participants expressed reluctance to purchase PrEP drugs with their own money; among those who were willing to purchase them, $18.2 \%$ were inclined to pay less than 100 RMB per month, $17.9 \%$ wanted to pay 100-200 RMB; and $17.3 \%$ wanted to pay $200-400$ RMB. Even when they were told that PrEP drugs need to be taken daily, $46 \%$ of the participants said they "definitely" would take them, $21 \%$ said they would "probably" do so, and nearly $20 \%$ said they would "probably not" or "definitely not" persist with treatment. When comparing two hypothetical PrEP drugs, $74 \%$ of the participants preferred to use drugs that were more expensive but with longer medication intervals, while only $14 \%$ chose to use the cheaper option but with a much higher use frequency. 


\section{Univariate predictors of willingness to use PrEP}

Fitted univariate logistic regression models (ie, those with only single predictors) are listed in Table 1 . We found that race, residence, and income level were significantly associated with the outcome variable, ie, willingness to use PrEP. Compared with female sex workers of other races, Han female sex workers seemed to be more likely to use PrEP (OR 1.415, $P=0.011$ ), and female sex workers registered as urban residents were more willing than those registered as rural residents to use PrEP (OR 1.342, $P=0.009$ ). Those with a monthly income of $5000+\mathrm{RMB}$ were more willing to use PrEP than those at lower income levels. Other features, such as age, level of educational attainment, and marital status, were not detected as being significant predictors when evaluated independently.

Among the variables measuring attitudes toward HIV/ AIDS, Table 3 shows the subsets that were significantly associated with or predictive of the outcome variable: participants who wanted to access knowledge about HIV/AIDS were more willing to use PrEP (OR 2.462, $P<0.0001$ ) than those who were not interested in acquiring knowledge about HIV/AIDS, and participants who had a nondiscriminatory attitude towards AIDS patients were more willing to use PrEP (OR 1.503, $P=0.004$ ) than those who had a discriminatory attitude.

Table 4 shows significant predictors of willingness to use PrEP among the list of AIDS-related behavioral and preventive measures: having a history of sexually transmitted infection (OR 1.850, $P<0.0001$ ); having a previous diagnosis of sexually transmitted disease (OR 1.758, $P=0.006$ ); a history of alcohol abuse (OR 1.269, $P=0.028$ ); having HIV/AIDS transmission knowledge (OR 1.689, $P=0.002$ ); recipient of free HIV/AIDS consultation in the last year (OR $1.379, P=0.003$ ); and having a history of STI prevention (OR 2.299, $P<0.0001$ ). We found that willingness to use PrEP was not statistically significantly related to types of substance use (K powder, ice, ecstasy), frequency of condom use, tests for HIV in the past, or a history of medical prevention of HIV/AIDS.

\section{Multivariate predictors of willingness to use PrEP}

All the significant factors identified above using bivariate models (three demographic, three attitude, and six knowledge and behavior variables) were included into a multivariable logistic regression analysis to predict future use of PrEP (ie, willing to use PrEP). In the model-fitting procedure, the strategy of stepwise variable selection was applied to include or exclude variables based on testing of whether their regression coefficients were significantly above zero. In the final logistic regression model chosen, the following six significant predictors (Table 5) were selected: Han ethnicity (adjusted odds ratio [AOR] 1.446, $P=0.011$ ), urban residence (AOR 1.302, $P=0.027$ ), having knowledge about HIV/AIDS transmission (AOR 1.817, $P=0.0007$ ), having a history of sexually transmitted disease (AOR 1.830, $P<0.0001$ ), having a history of use of preventative medication for sexually transmitted disease (AOR 2.547, $P<0.0001$ ), and intent to access knowledge about HIV/AIDS (AOR 2.153, $P<0.0001)$.

\section{Discussion}

This survey was part of a feasibility study preparing for a large-scale clinical trial of PrEP in China for the first time. The study indicates that a relatively high $(69 \%)$ proportion of surveyed female sex workers would be willing to use PrEP for HIV prevention when it was assumed that PrEP would be safe and effective. If the drugs were further assumed to be offered free and widely used, the willingness to use PrEP

Table 5 Fitted multivariable logistic regression model for predicting willingness to use PrEP

\begin{tabular}{|c|c|c|c|}
\hline Characteristic & AOR & $95 \% \mathrm{Cl}$ & $P$ value \\
\hline Race & & & 0.011 \\
\hline Han & 1.446 & $1.087-1.924$ & \\
\hline Others & 1.000 & & \\
\hline Registered residency & & & 0.027 \\
\hline Urban residency & 1.302 & $1.030-1.645$ & \\
\hline Rural residency & 1.000 & & \\
\hline Has HIVIAIDS & & & 0.0007 \\
\hline \multicolumn{4}{|l|}{ transmission knowledge } \\
\hline Yes & 1.817 & $1.285-2.568$ & \\
\hline No & 1.000 & & \\
\hline STI history & & & $<0.0001$ \\
\hline Yes & 1.830 & $\mathrm{I} .43 \mathrm{I}-2.340$ & \\
\hline No & 1.000 & & \\
\hline Ever used STI & & & $<0.000 \mathrm{I}$ \\
\hline \multicolumn{4}{|l|}{ preventive medication } \\
\hline Yes & 2.547 & $|.67|-3.882$ & \\
\hline No & 1.000 & & \\
\hline Wish to access & & & $<0.0001$ \\
\hline \multicolumn{4}{|l|}{ knowledge of HIVIAIDS } \\
\hline Yes & 2.153 & I.685-2.752 & \\
\hline No & 1.000 & & \\
\hline
\end{tabular}

Abbreviations: AIDS, acquired immune deficiency syndrome; $\mathrm{Cl}$, confidence interval; HIV, human immunodeficiency virus; AOR, adjusted odds ratio; PrEP, preexposure prophylaxis; STI, sexually transmitted infection. 
increased to $80 \%$. Such support levels for PrEP among the female sex workers surveyed provides strong evidence of acceptance of a PrEP clinical trial and related intervention programs in China among female sex workers in the future. By demonstrating the benefits and feasibility of PrEP for HIV prevention in hesitant users and initiating promotion by users with a strong positive attitude, more people would use PrEP.

Although we have not seen any published assessment of willingness to use PrEP among female sex workers, there have been three studies in MSM groups, with reported acceptance rates of $67 \%,{ }^{18} 68.9 \%,{ }^{19}$ and $74.4 \% .{ }^{8}$ These estimates are fairly consistent with our findings in the present research. Compared with condom use, an advantage of PrEP is that users do not need the consent of their sexual partners to use it. ${ }^{20}$ Considering that in China, for tradition and cultural reasons, women often play a passive role or have a weak position in sexual activity, PrEP would be a particularly appropriate and effective option for HIV prevention. ${ }^{21}$ Therefore, it is likely that female sex workers would have a greater likelihood of embracing PrEP than other groups, such as MSM.

Female sex workers who had previously noticed symptoms of sexually transmitted infection and had previously used drugs to prevent venereal disease were found to be more willing to accept PrEP for HIV/AIDS prevention. Symptoms of sexually transmitted disease were noticed by $35.1 \%$ of the female sex workers, but less than $10 \%$ of them actually went for diagnosis or received treatment. Fearing the pain and burden resulting from a sexually transmitted disease, such as discrimination and privacy concerns, $12 \%$ of female sex workers chose to use over-the-counter medicines to prevent sexually transmitted disease. These people would be more willing to use PrEP in preventing HIV infection than others without experience of prevention of sexually transmitted disease (OR 1.858). Our study also shows that economic and cultural factors play an important role in the willingness of female sex workers to use PrEP. Female sex workers with a high income or living in an urban area were more willing to use PrEP, and those with a better understanding of HIV/AIDS or a strong desire to receive related education would be more likely to use PrEP. A comprehensive understanding of the infection, dissemination, and hazards of HIV/AIDS among female sex workers would make the prevention and control of HIV/AIDS more effective, especially among female sex workers, but due to the nature of this study we do not have supportive data for this.
Although female sex workers had a strong willingness to use PrEP, their knowledge about PrEP was rather limited. Only $16.5 \%$ had heard of PrEP before participation, and only $1.4 \%$ had used PrEP before, which is consistent with results reported for MSM groups, eg, $16 \%$ and $0.8 \%$, respectively, in California, ${ }^{18} 23.7 \%$ and $1.7 \%$ in New York City, ${ }^{19} 25 \%$ and $5 \%$ in four other US cities, ${ }^{22}$ and $18.9 \%$ and $0.3 \%$ in another seven US cities. ${ }^{23}$ Along with our survey staff, other important sources of information on PrEP included health professionals, the Internet, television, newspapers, and communication with friends. As a new prevention strategy, public understanding and awareness of PrEP are key to developing successful promotion and intervention programs.

The safety and efficacy of PrEP drugs are the two aspects of most concern to female sex workers. Although previous clinical studies have shown that PrEP is effective in preventing and reducing HIV infection, ${ }^{14-16,24}$ and a number of mathematical models have demonstrated that the PrEP strategy could significantly reduce HIV infection rates among high-risk groups, ${ }^{25-27} \mathrm{PrEP}$ is still under development. ${ }^{20,21}$ The price of PrEP drugs, their prescription, and related marketing channels are also the focus of attention. More than half of the female sex workers interviewed said that they did not want to spend more than 400 RMB per month on PrEP, and most of them preferred to take the drug at relatively long intervals if possible. Even though few people liked to take medicine on a daily basis, they "definitely" would persist with the treatment if required to do so. However, the drug formulation used needs to be convenient for the patient's lifestyle. It would be ideal if the timing of a medication dose was not critical, such that occasionally missing a dose would not have a negative impact. Therefore, the pharmacokinetics and toxicological characteristics of PrEP drugs are key to the success of the strategy. ${ }^{28}$

Even if clinical trials did confirm the safety and efficacy of PrEP, many issues still need to be resolved. ${ }^{8,19-21,29-33}$ For example, the effectiveness and compliance demonstrated in the trial may carry over to the general population, but they may decrease in natural contexts due to reasons such as behavioral disinhibition, risk compensation, and cultural or social barriers. The PrEP intervention within the above cultural and social contexts should be designed carefully in order to maximize the effectiveness and compliance, considering the controversial findings from various studies on how Truvada prevents HIV transmission in HIV-negative men and women who take it every day. ${ }^{14}$ It is important that we tackle HIV infection among female sex workers and other 
high-risk groups in the future, especially with regard to how people negotiate condom use in relationships, how well they maintain compliance with medication, and how we look at sexuality and sexual behavior. As stated by Kim et al, ${ }^{21}$ "there is no single prevention scheme that can effectively prevent HIV transmission worldwide". Hence it is emphasized that PrEP should not completely replace other preventive means, such as comprehensive health education and condom use.

There are several limitations to this research. First, because of the underground nature of the population studied, we used a variety of methods to recruit subjects. This could have led to selection bias and limited the generalizability of our research findings. Second, this study has a cross-sectional design, and asks participants to recall events that happened in the past. This would be associated with problems such as recall bias and accuracy. Third, because the questionnaire was self-administered under the supervision of field investigators, the results may be biased due to a desire on the part of the participants to provide socially acceptable answers. In other words, when facing the survey staff, the participants tend to answer questions in a way that would satisfy the people around them. Finally, we should be cautious about the concept of "willingness to use" PrEP because anticipated willingness does not always translate well into actual behavior.

\section{Conclusion}

This study shows that the majority of female sex workers would be willing to use PrEP for the purpose of HIV/AIDS prevention so long as it is proven to be effective and safe. Because the majority of female sex workers are rarely aware of information or knowledge of PrEP, materials for public education are greatly needed and should be carefully designed to target high-risk groups. Users should be educated on the risks and benefits of taking PrEP when developing programs for promotion of PrEP strategies for HIV prevention in the future. For the first time in China, we have a study providing evidence of acceptance of PrEP among female sex workers and identifying factors that can potentially be utilized to enhance the quality of this strategy in the future. It offers a clear guideline for creating a protocol for our future clinical trial of PrEP, and for creating tailored prevention and control of HIV infections among high-risk populations in China.

\section{Acknowledgments}

This study was supported by the Ministry of Science and Technology of the People's Republic of China
(2008ZX10001-016). We are grateful to all participants, investigators, and health personnel from local offices of Centers for Disease Control and Prevention.

\section{Disclosure}

The authors report no conflicts of interest in this work.

\section{References}

1. Joint United Nations Programme on HIV/AIDS. World AIDS Day Report 2011 - how to get to zero: faster, smarter, better. Available from: http://www.unaids.org/en/. Accessed June 6, 2012.

2. National Center for AIDS/STD Prevention and Control. 2011 Estimates for the HIV/AIDS epidemic in China. Available from: http://www. chinaids.org.cn/n1971/n2151/n777994.files/n777993.pdf. Accessed June 1, 2012.

3. Joint United Nations Programme on HIV/AIDS, Ministry of Health of the People's Republic of China. China AIDS Response Progress Report, 2012. Available from: http://www.unaids.org/en/dataanalysis/ monitoringcountryprogress/progressreports/2012countries/. Accessed June 1, 2012.

4. HIV and AIDS Data Hub for Asia-Pacific. China Country Reviews March 2011. Available from: http://aidsdatahub.org/dmdocuments/ China_Country_Review_2011_HIV_and_AIDS_Data_Hub_for_Asia_ Pacific.pdf. Accessed June 1, 2012.

5. Zhang DP, Lv F, Wang LY, et al. Estimating the population of female sex workers in two Chinese cities on the basis of the HIV/AIDS behavioural surveillance approach combined with a multiplier method. Sex Transm Infect. 2007;83:228-231.

6. HIV and AIDS Data Hub for Asia-Pacific. Sex work and HIV, China. Available from: http://aidsdatahub.org/dmdocuments/sex_work_hiv_ china.pdf. Accessed June 1, 2012.

7. Gill B, Huang YZ, Lu XQ. Demography of HIV/AIDS in China: A Report of the Task Force on HIV/AIDS Center for Strategic and International Studies. Available from: http://csis.org/files/media/csis/ pubs/070724_china_hiv_demography.pdf. Accessed May 29, 2012.

8. Mimiaga MJ, Case P, Johnson CV, Safren SA, Mayer KH. Preexposure antiretroviral prophylaxis (PrEP) attitudes in high risk Boston area MSM: limited knowledge and experience, but potential for increased utilization after education. J Acquir Immune Defic Syndr. 2009;50:77-83.

9. Lynn AP, Tony H, Harold WJ. Pre-exposure prophylaxis for HIV infection: what if it works? Lancet. 2007;370:89-93.

10. Clauson KA, Polen HH, Joseph SA, Zapantis A. Role of the pharmacist in pre-exposure chemoprophylaxis (PrEP) therapy for HIV prevention. Pharm Pract. 2009;7:11-18.

11. van Griensven F, Thienkrua W, Sukwicha W, et al. Sex frequency and sex planning among men who have sex with men in Bangkok, Thailand: implications for pre- and post-exposure prophylaxis against HIV infection. J Int AIDS Soc. 2010;13:13.

12. García-Lerma JG, Paxton L, Kilmarx PH, Heneine W. Oral preexposure prophylaxis for HIV prevention. Trends Pharmacol Sci. 2010;31:74-81.

13. Supervie V, García-Lerma JG, Heneine W, Blower S. HIV, transmitted drug resistance, and the paradox of preexposure prophylaxis. Proc Natl Acad Sci U S A. 2010;107:12381-12386.

14. Global Advocacy for HIV prevention. PrEP Clinical Trials. Available from: http://www.avac.org/ht/d/sp/i/326/pid/326. Accessed April 25, 2012.

15. Cohen J. HIV/AIDS, at last, vaginal gel scores victory against HIV. Science. 2010;329:374-375.

16. Grant RM, Lama JR, Anderson PL, et al. Preexposure chemoprophylaxis for HIV prevention in men who have sex with men. $N$ Engl J Med. 2010;363:2587-2599. 
17. Cunningham W, Galea J, Kinsler J, et al. The acceptability of preexposure prophylaxis (PrEP) for HIV prevention in Lima, Peru. Abstract WEPE0260 presented at the International AIDS Society Conference, August 3-8, 2008, Mexico City, Mexico.

18. Liu AY, Hittredge PV, Vittinghoff E, et al. Limited knowledge and use of HIV-post- and pre-exposure prophylaxis among gay and bisexual men. J Acquir Immune Defic Syndr. 2008;47:241-247.

19. Golub SA, Kowalczyk W, Weinberger CL, Parsons JT. Pre-exposure prophylaxis and predicted condom use among high-risk men who have sex with men. J Acquir Immune Defic Syndr. 2010;54:548-555.

20. AVAC. Global Advocacy for AIDS prevention. PrEP Primer: An introduction to pre-exposure prophylaxis (PrEP) research for HIV prevention. Available from: http://www.avac.org/ht/a/GetDocumentAction/i/4147. Accessed April 10, 2012.

21. Kim SC, Becker S, Dieffenbach C, et al. Planning for pre-exposure prophylaxis to prevent HIV transmission: challenges and opportunities. $J$ Int AIDS Soc. 2010;13:24.

22. Kellerman SE, Hutchinson AB, Begley EB, et al. Knowledge and use of HIV pre-exposure prophylaxis among attendees of minority gay pride events, 2004. J Acquir Immune Defic Syndr. 2006;43:376-377.

23. Voetsch AC, Heffelinger JD, Begley EB, Jafa-Bhushan K, Sullivan PS. Knowledge and use of preexposure and postexposure prophylaxis among attendees of minority gay pride events, 2005 through 2006. J Acquir Immune Defic Syndr. 2007;46:378-380.

24. García-Lerma JG, Otten RA, Qari SH, et al. Prevention of rectal SHIV transmission in macaques by daily or intermittent prophylaxis with emtricitabine and tenofovir. PLoS Med. 2008;5(2):e28.
25. Abbas UL, Anderson RM, Mellors JW. Potential impact of antiretroviral chemoprophylaxis on HIV-1 transmission in resource-limited settings. PLoS One. 2007;2:e875.

26. Vissers D, Voeten H, Nagelkerke N, et al. The impact of pre-exposure prophylaxis (PrEP) on HIV epidemics in Africa and India: a simulation study. PLoS One. 2008;3:e2077.

27. Paltiel AD, Freedberg KA, Scott CA, et al. HIV Pre-exposure prophylaxis (PrEP) in the United States: impact on lifetime infection risk, clinical outcomes, and cost-effectiveness. Clin Infect Dis. 2009;48:806-815.

28. Derdelinckx I, Wainberg MA, Lange JMA, et al. Criteria for drugs used in pre-exposure prophylaxis trials against HIV infection. PLoS Med. 2006;3:e454.

29. Smith SM. Pre-exposure chemoprophylaxis for HIV: it is time. Retrovirology. 2004;1:16.

30. Okwundu CI, Okoromah CA. Antiretroviral pre-exposure prophylaxis (PrEP) for preventing HIV in high-risk individuals [Abstract]. Cochrane Database Syst Rev. 2009;1:CD007189.

31. Guest G, Shattuck D, Johnson L, et al. Changes in sexual risk behavior among participants in a PrEP HIV prevention trial. Sex Transm Dis. 2008;35:1002-1008.

32. Eaton LA, Kalichman S. Risk compensation in HIV prevention: implications for vaccines, microbicides, and other biomedical HIV prevention technologies [Abstract]. Curr HIV/AIDS Rep. 2007;4:165-172.

33. Rosengarten M, Michael M. The performative function of expectations in translating treatment to prevention: The case of HIV pre-exposure prophylaxis, or PrEP. Soc Sci Med. 2009;69:1049-1055.
HIV/AIDS - Research and Palliative Care

\section{Publish your work in this journal}

HIV/AIDS - Research and Palliative Care is an international, peerreviewed open-access journal focusing on advances in research in HIV, its clinical progression and management options including antiviral treatment, palliative care and public healthcare policies to control viral spread. The journal welcomes original research, basic science,

\section{Dovepress}

clinical \& epidemiological studies, reviews \& evaluations, expert opinion \& commentary, case reports \& extended reports. The manuscript management system is completely online and includes a very quick and fair peer-review system. Visit http://www.dovepress.com/ testimonials.php to read real quotes from published authors. 